\title{
Tampão genital de Actinote Hübner, como caráter taxonômico (Lepidoptera, Nymphalidae, Acraeinae) ${ }^{1}$
}

\author{
Márlon Paluch ${ }^{2,3}$ \\ Mirna M. Casagrande 2,4 \\ Olaf H. H. Mielke 2,4
}

\begin{abstract}
Sphragis of Actinote Hübner, as a taxonomic character (Lepidoptera, Nymphalidae, Acraeinae). The sphragis morphology of seven species of Actinote Hübner, [1819] from south Brazil are presented and discussed comparatively. Their significant differences and scales were revealed with SEM photographs. They can be usable as characters to identify species.
\end{abstract}

KeYwords. Actinote; Morphology; Scales; Sphragis; Taxonomy.

As fêmeas de Actinote Hübner, [1819], encontradas no sul do Brasil, são de difícil identificação, devido às semelhanças fenotípicas, associadas em algumas espécies, a uma grande variação intraespecífica. D'AlmeIDA (1958) mencionou esta mesma dificuldade e sugeriu que a correta identificação só seria possível a partir de fêmeas obtidas de ovos de uma única postura. Neste artigo apresentamos detalhes da morfologia do tampão genital, de sete das dez espécies listadas por C. MIELKE (1994) de ocorrência em Curitiba, Paraná: A. mamita mitama (Schaus, 1902); A. surima (Schaus, 1902); A. carycina Jordan, 1913; A. melanisans Oberthür, 1917; A. genitrix D'Almeida, 1922; A. dalmeidai Francini, 1996 e A. catarina Penz, 1996, as duas últimas mencionadas como espécies próximas à A. alalia (C. Felder \& R. Felder, 1860). Penz \& Francini (1996) ao descreverem três espécies novas, $A$. dalmeidai Francini, 1996; A. catarina Penz, 1996 e A. bonita Penz, 1996, ilustraram o tampão genital das duas últimas e também de $A$. surima.

A primeira referência para esta estrutura foi feita por CHAPMAN (1900) e denominada como "pouch", para Parnassius Schneider, 1785, com base em uma única observação, como uma estrutura depositada na fêmea, durante o pareamento e sugerindo que a mesma poderia estar relacionada com a oviposição.

Posteriormente Marshall (1901) aprofundou as observações e encontrou em Acraea Fabricius, 1807, estrutura similar àquela descrita por CHAPMAN (1900). Concluiu, com base em suas observações que a oviposição não apresentava nenhuma relação com o "pouch" já que quando o ovo era depositado sobre a planta, não chegava a encostar na estrutura e sim, que poderia atuar como uma proteção para as fêmeas, evitando desta forma outras cópulas. Porém, uma questão ainda não estava clara, ou seja, por que as fêmeas necessitam de tal proteção? Sugeriu, também, que a razão para esta proteção poderia estar relacionada com a forma como ocorre a cópula, isto é, a mais comum entre os lepidópteros é aquela precedida por um cortejamento, o que não acontece com Acraea onde a cópula se dá por ataque.

Em suas observações Marshall (1901) registrou que tal proteção não era absoluta, desde que observou três femeas de Acraea, nas quais, a estrutura estava duplicada e ambas tinham a forma distorcida indicando que um segundo pareamento foi realizado imediatamente após o primeiro, enquanto a secreção estava em condição viscosa. Porém, estas exceções não indicam que a teoria de que a secreção quando endurecida, ofereça obstrução suficiente para evitar a cópula repetida com outros machos, porém, uma dupla fecundação poderia ser possível.

Em estudos com Acraea, ELtringham (1912) utilizou o termo "sphragis", para esta mesma estrutura, definindo-a como uma massa de material ceroso e duro, colocada na parte ventral do abdome da fêmea enquanto em cópula.

EHRLich \& EHRLich (1978) relataram que a estrutura era produzida por secreções da glândula acessória do macho

1. Contribuição n 1323 do Departamento de Zoologia, Universidade Federal do Paraná.

2. Departamento de Zoologia, Universidade Federal do Paraná. Caixa Postal 19020, 81531-980 Curitiba-PR, Brasil.

3. Bolsista Doutorado-CNPq.

4. Pesquisador CNPq. 
durante a cópula, depois depositada no duto da bolsa da fêmea, funcionando como um "mating plug".

Pierre (1985) indicou que a estrutura era um caráter semaforonte de machos, estrutural e comportamental.

SOURAKOV \& EMmel (1997) em estudos a respeito dos hábitos de acasalamento em Acraea, sugeriram que uma característica peculiar do gênero, que evoluiu como um mecanismo anticoncepcional físico, era representado pelo "sphragis", um "mating plug" secretado pelo macho durante a cópula e preso aos esternos terminais da fêmea, bloqueando a entrada de espermatóforos de machos subseqüentes. Apresentaram uma foto de um casal de Acraea epaea (Cramer, 1779) em cópula, com um segundo macho pousado sobre as asas da fêmea durante o processo, na espera de que a fêmea se tornasse disponível para um segundo acasalamento.

Esta estrutura tem sido discutida por MunRoe (1961); SAigusa \& Lee (1982) apud Miller (1987) em outros gêneros de Papilionidae como: Luehdorfia Crüger, 1878 e Bhutanitis Atkinson, 1873 (Parnasiinae) e por Miller (1987) em espécies de Troidini (Papilioninae).

Visando contribuir para um melhor entendimento taxonômico e subsidiar uma classificação para o grupo, apresenta-se a caracterização das variações desta estrutura, para a qual utilizamos o termo tampão genital. Apresentam-se além do tampão genital como um todo, aspectos das escamas em microscopia eletrônica de varredura como possível auxílio na identificação de algumas fêmeas de Actinote e como um caráter taxonômico de machos.

Escamas, como apresentado em estudos anteriores por AnKen (1996) com asas de Heliconiinae, podem apresentar diferenças consideráveis entre as espécies Heliconius erato (Linnaeus, 1758) e H. besckei (Ménétriés, 1857), desta afirmação podemos supor que escamas do corpo e das asas, associadas àquelas apresentadas no tampão genital podem resultar em um bom caráter, quando comparadas às escamas das asas e corpo dos machos com aquelas encontradas formando o tampão genital.

\section{MATERIAL E MÉTODOS}

Os exemplares de Actinote, utilizados para este estudo são provenientes de Curitiba, 900 - 950m; Piraquara (Mananciais da Serra), 897m, Paraná e de Urubici, 1800m, Santa Catarina, Brasil.

Adultos de seis espécies obtidos de larvas coletadas no último ínstar, foram mantidos em gaiolas cúbicas de $60 \mathrm{~cm}$ de aresta junto às plantas hospedeiras envasadas, alimentados com solução de $10 \%$ de mel comum e submetidos a experimentos de reprodução em cativeiro. Exemplares adultos de $A$. catarina foram provenientes de coletas em campo. As fêmeas de Actinote utilizadas neste estudo foram posteriormente usadas para estudo morfológico em microscopia eletrônica de varredura. A variação intraespecífica foi analisada em microscópio estereoscópico.

\section{RESULTADOS E DISCUSSÃO}

O tampão genital, denominação aqui utilizada para "pouch", "sphragis" e "mating plug" nas sete espécies de Actinote analisadas, é uma estrutura simétrica depositada pelos machos nas fêmeas durante o processo de acasalamento, funcionando como uma barreira física para outros acasalamentos. $\mathrm{O}$ tampão é colocado ventralmente entre o sexto esterno e a papila anal, cobrindo toda a placa genital da fêmea podendo, ou não, recobrir o sexto e o sétimo esterno.

É formado por substância aglutinante que endurece em contato com o ar juntamente com as escamas oriundas da membrana intersegmentar 8-9 dos machos (Fig. 1), estas escamas estão compactadas e a sua disposição no macho determina diretamente a forma do tampão genital (PIERRE 1985).

Os machos de seis espécies (exceção de A. catarina) utilizados na reprodução em cativeiro morreram entre 1 a 3 dias após a cópula. Três machos foram mantidos com 3-5 fêmeas. Todas as fêmeas que copularam apresentaram um único tampão e realizaram a oviposição na planta hospedeira com ovos fertilizados; entre as que não apresentaram o tampão genital, apenas uma de $A$. melanisans realizou a oviposição mas os ovos não embrionaram. Uma fêmea desta espécie, coletada em Morro Alto, Morretes, Paraná, apresentou evidências de uma segunda cópula já que apresentou tampão duplicado, posto de forma distorcida lateralmente aos últimos esternos do abdome sobre o tampão do primeiro acasalamento (Fig. 2), semelhante ao que MARSHALl (1901) registrou para as fêmeas de Acraea na África.

Outro aspecto que corrobora as sugestões de MARSHALL (1901) sobre a razão da necessidade do tampão genital é que nas espécies tratadas neste estudo a cópula ocorre por captura, sem corte, o macho, algumas vezes, derruba a fêmea no chão, tal a violência do ataque.

Todos os machos utilizados no experimento foram dissecados e comparados com machos virgens obtidos de criação em laboratório, sendo que os machos que copularam apresentaram apenas resquícios de escamas formadoras do tampão, indicando que um macho pode formar apenas um tampão genital e, possivelmente, em ambiente natural copule apenas uma vez.

Os tampões das sete espécies analisadas (Figs. 5-25) são formados por dois tipos de escamas e por substância aglutinante. Estas escamas encontram-se inseridas na membrana intersegmentar que anteriormente liga-se à margem posterior do oitavo tergo e à margem posterior da pleura e posteriormente em toda a margem anterior do tegume até a região basal do braço, formando uma bolsa invertida entre a projeção anterior do saco e o oitavo tergo, acima do edeago (Fig. 1). Algumas espécies africanas como Acraea zitja Boisduval, 1833 possuem o tampão semelhante ao do seu grupo-irmão neotropical Actinote, formado por escamas e substância aglutinante (Fig. 3), outras, como Acraea igati Boisduval, 1833 apresentam o tampão formado apenas por substâncias cerosas constituindo uma estrutura amorfa (Eltringham 1912) (Fig. 4). 

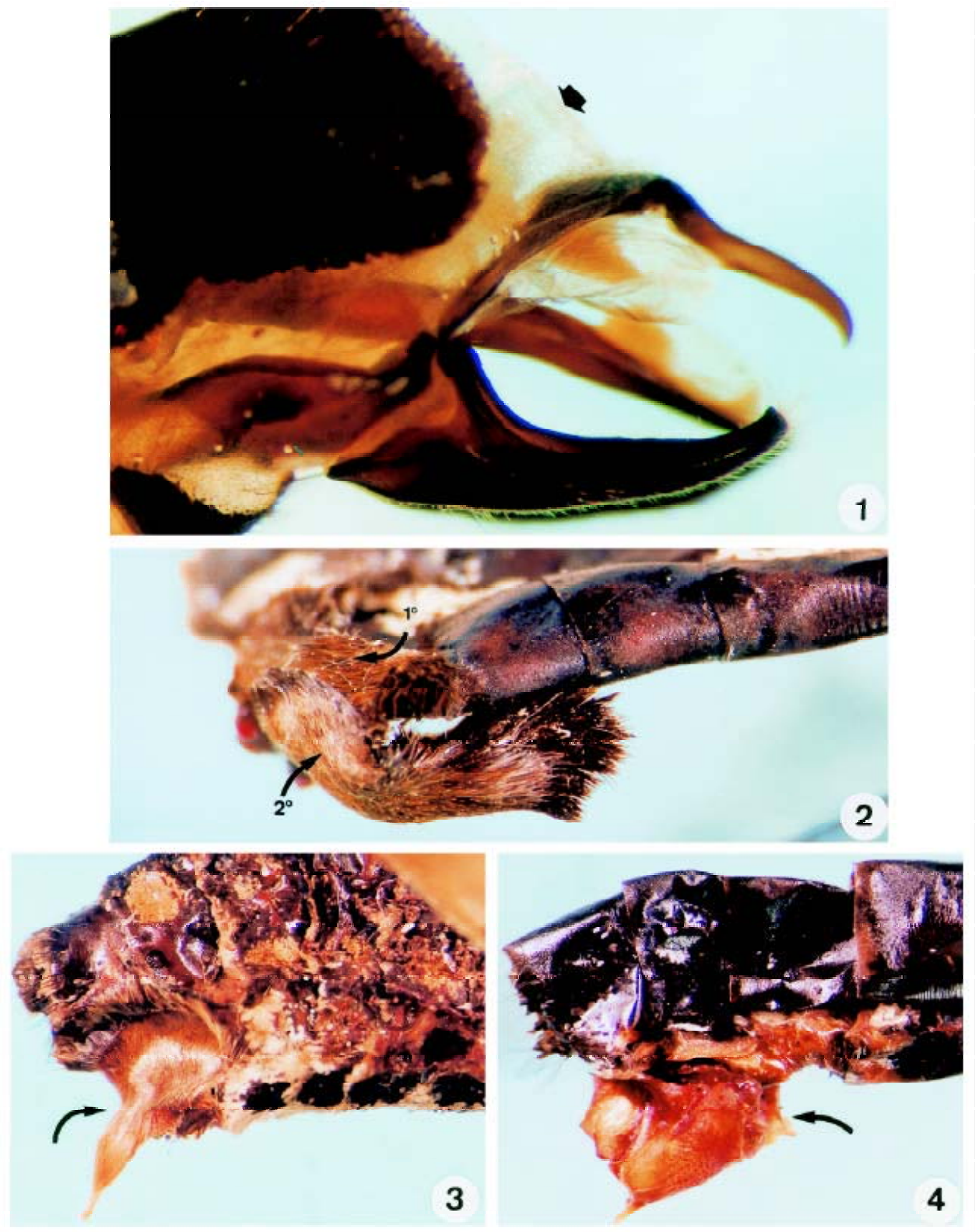

Figs. 1-4. 1. Actinote genitrix. Macho, vista lateral do VIII tergo e esterno, membrana intersegmentar VIII-IX indicada pela seta e genitália parcialmente evertida; 2. Actinote melanisans. Fêmea, vista látero-ventral do abdome, com o primeiro e segundo tampão genital, sendo este colocado lateralmente aos esternos sobre o primeiro; 3. Acraea zitja. Fêmea, vista lateral do abdome, tampão genital formado por escamas e substância aglutinante; 4. Acraea igati. Fêmea, vista lateral do abdome, tampão genital formado por substância cerosa. 

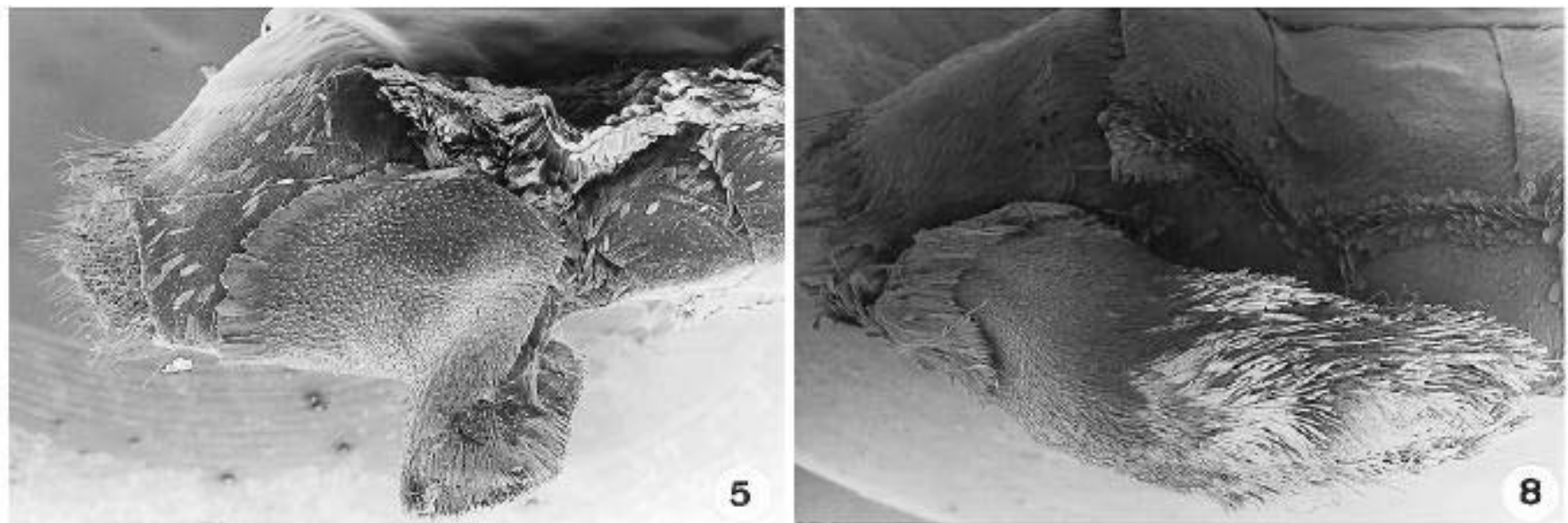

$1 \mathrm{~mm}$
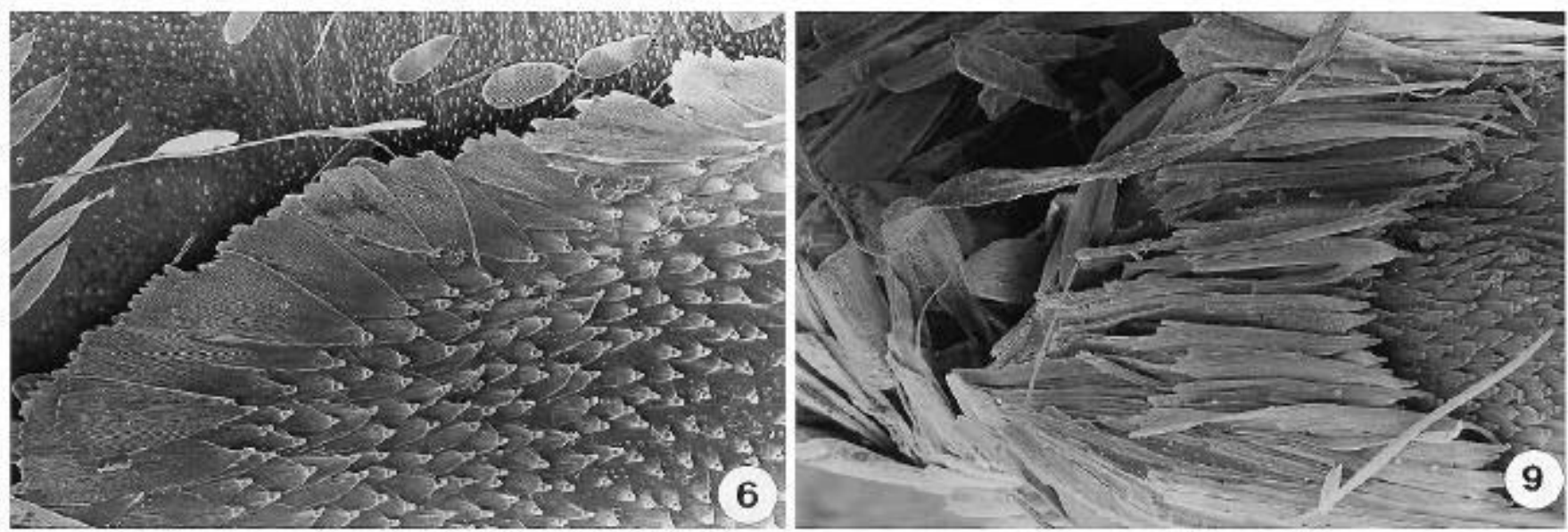

$200 \mu \mathrm{m}$
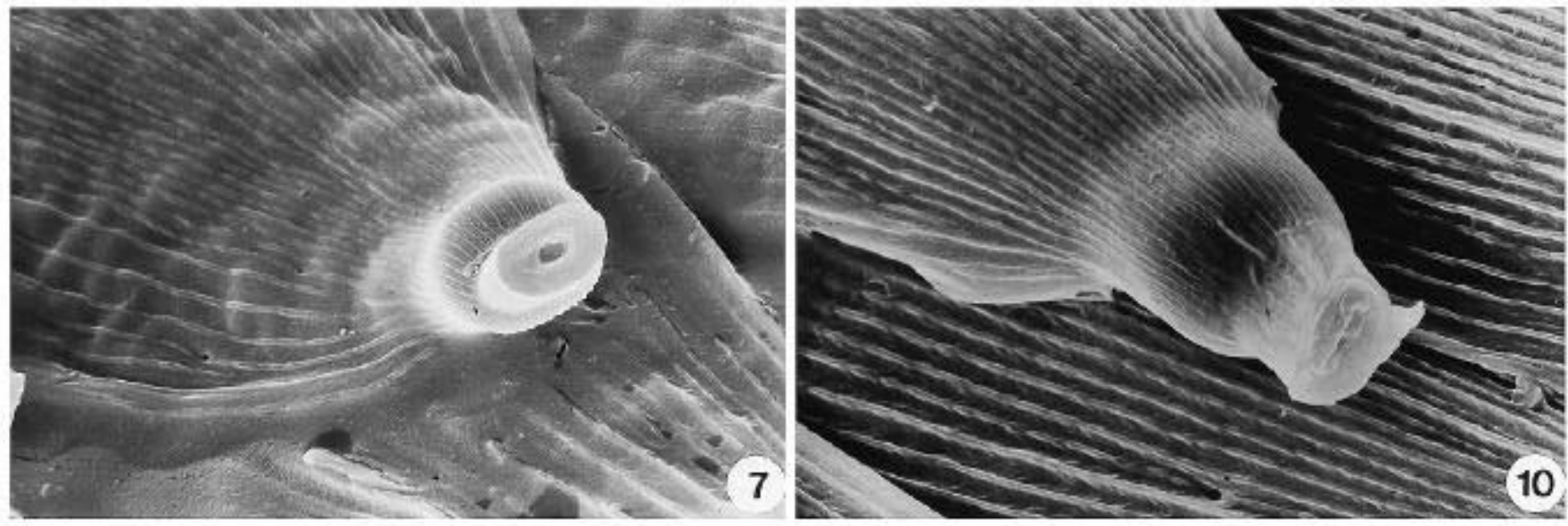

$10 \mu \mathrm{m}$

Figs. 5-7. Actinote mamita mitama. 5, tampão genital; 6, detalhe do imbricamento das escamas; 7, detalhe da região basal da escama. Figs. 8-10. Actinote surima. 8, tampão genital; 9, Detalhe do imbricamento das escamas; 10, detalhe da região basal da escama.

Um dos tipos de escamas é filiforme e aparece em todas as espécies, não apresentando variação interespecífica significativa. Encontram-se na região interna do tampão quando depositado na fêmea e podem ser vistas no seu ápice (Figs 5, 8, $11,14,17,20$ e 23 ).

As diferenças observadas nas escamas que revestem externamente os tampões das sete espécies são notáveis, mostrando distinções morfológicas interespecíficas, assim como, na forma geral dos tampões. As escamas encontram-se imbricadas umas sobre as outras (Figs 6, 9, 12, 15, 18, 21 e 24) sendo possível a sua visualização completa apenas na margem distal do tampão (Figs 5, 8, 11, 14, 17, 20 e 23). Entretanto, 

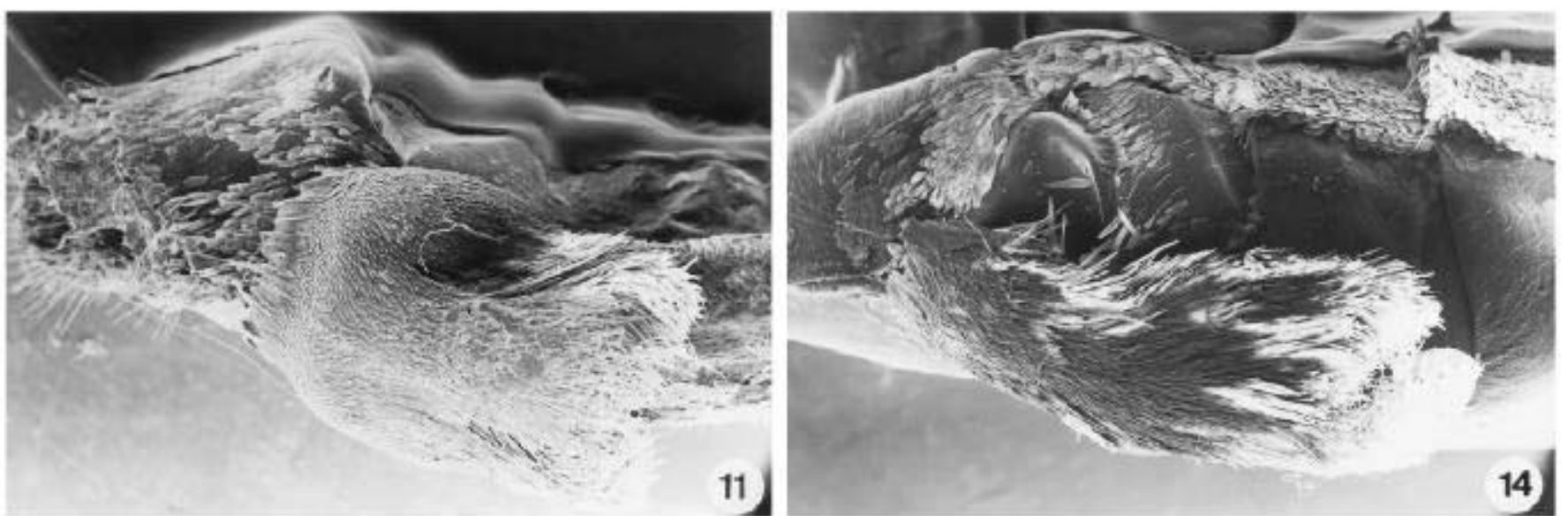

11
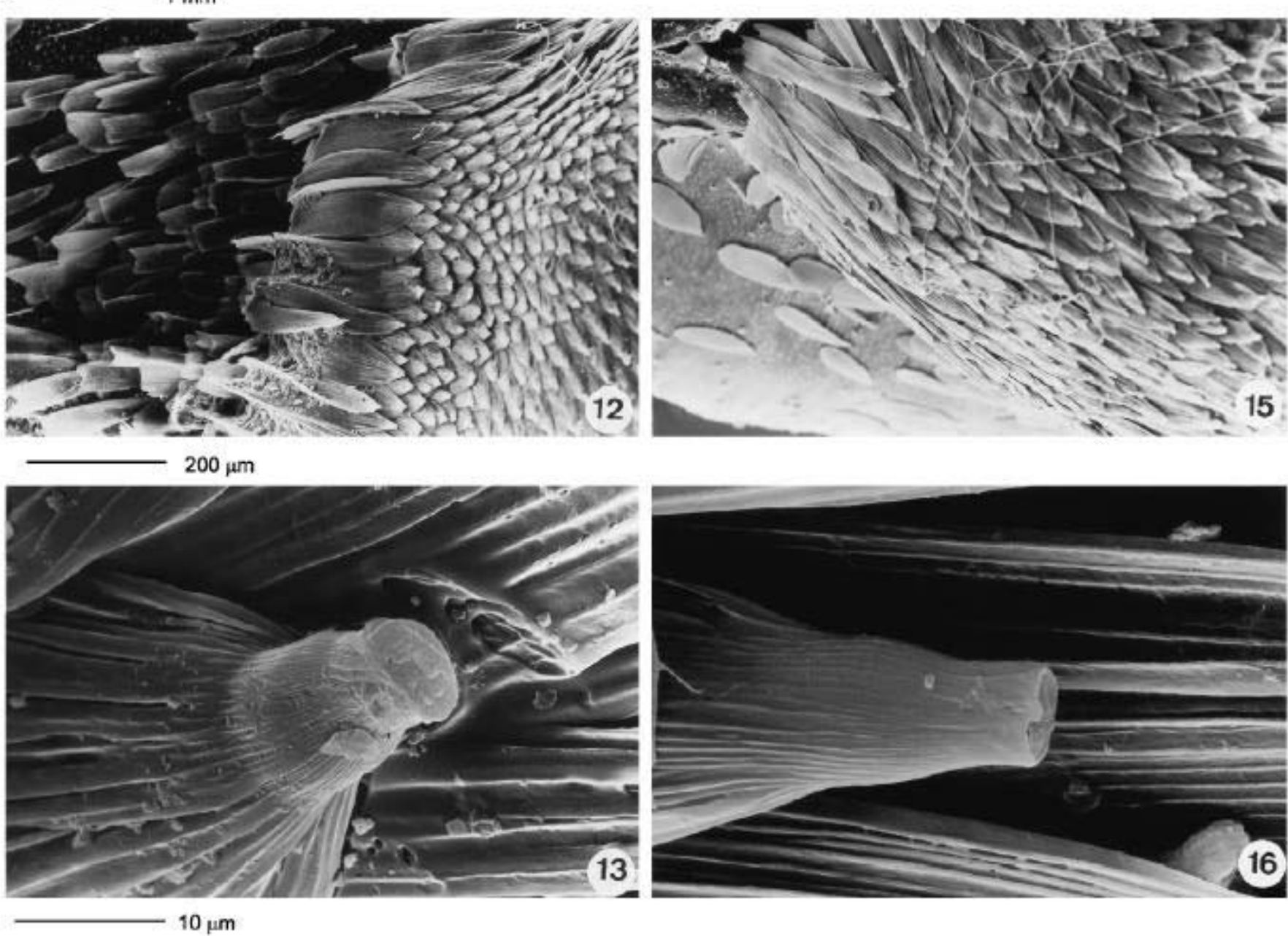

Figs. 11-13. Actinote carycina. 11, tampão genital; 12, detalhe do imbricamento das escamas; 13, detalhe da região basal da escama. Figs. 14-16. Actinote melanisans. 14, tampão genital; 15, detalhe do imbricamento das escamas; 16, detalhe da região basal da escama.

algumas espécies dos grupos "amarelo" como A. carycina, $A$. melanisans e A. genitrix e "laranja" como A. mamita mitama, A. surima, $A$. dalmeidai e $A$. catarina sendo as três ultimas do "complexo mimético alalia" ( Brown \& Francini 1990), se interrelacionam através de semelhanças no padrão morfológico, tendo quatro situações distintas para a região basal das escamas: A. mamita mitama e A. carycina apresentam escamas com região basal arredondada (Figs 7 e 13); A. surima, $A$. melanisans $\mathrm{e}$ A catarina apresentam escamas com região basal alongada (Figs 10, 16 e 25); A. genitrix, escamas com duas projeções laterais na região basal (Fig. 19) e A. dalmeidai apresenta escamas com região basal em forma de aba 

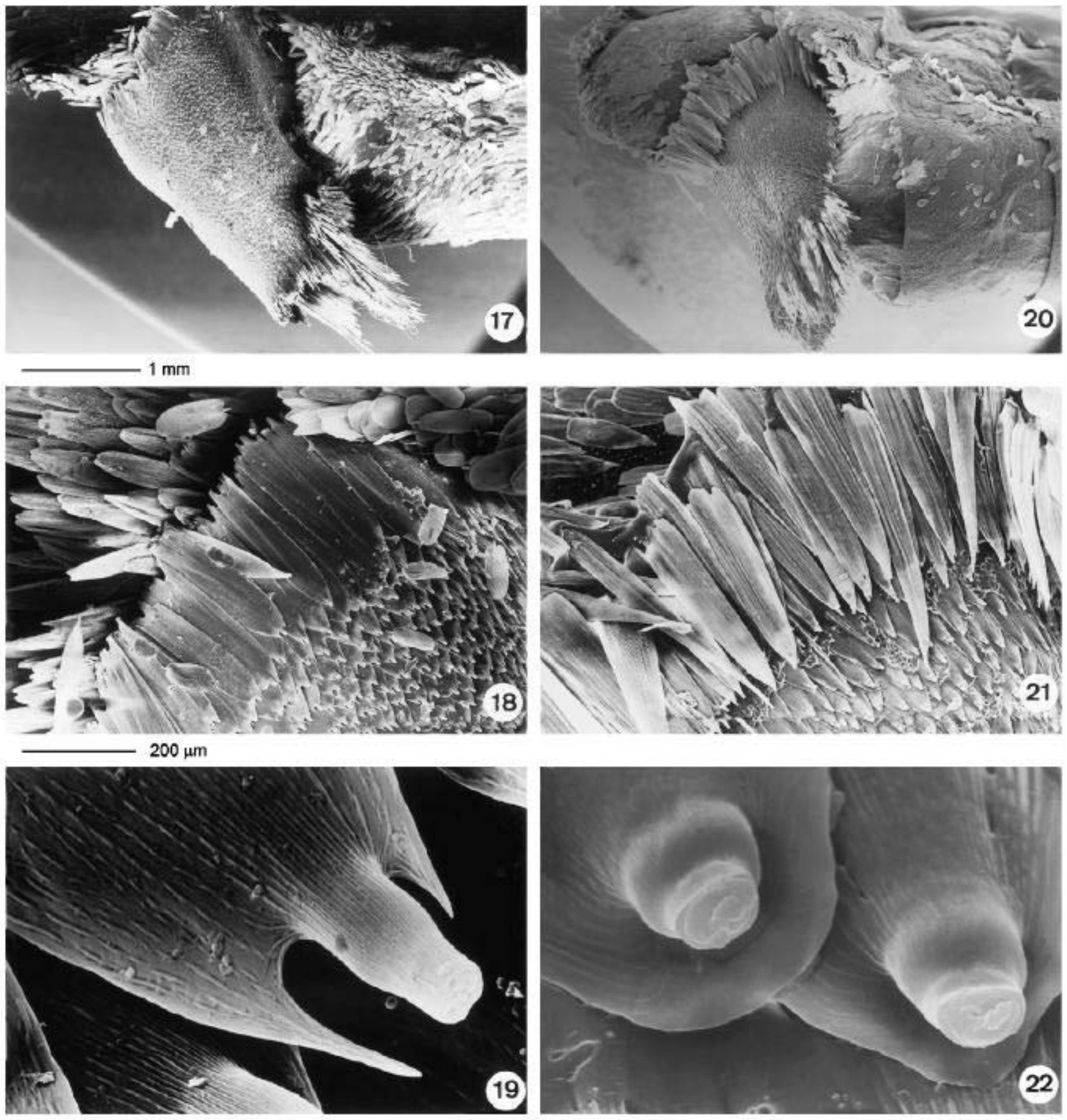

$10 \mu \mathrm{m}$

Figs. 17-19. Actinote genitrix. 17, tampão genital; 18, detalhe do imbricamento das escamas; 19, detalhe da região basal da escama. Figs. 20-22. Actinote dalmeidai. 20, tampão genital; 21, detalhe do imbricamento das escamas; 22, detalhe da região basal da escama.

arredondada logo em seguida à área base de inserção (Fig. 22).

Quanto à base de inserção das escamas, é possível observar que $A$. mamita mitama e A. catarina têm em comum escamas com a base de inserção oca (Figs 7 e 25) e as demais, com base maciça.

Considerando-se dois estados de caráter para a forma geral dos tampões associado à forma dos esternos VII-VIII do abdome da fêmea, A. surima, A. carycina e A. melanisans apresentam o ápice do tampão genital em contato com o sexto e recobrindo totalmente o sétimo esterno, que apresenta uma ligação uniforme entre o VII esterno e a placa genital (Figs 8, 11, 14). A. mamita mitama apresenta este mesmo padrão 

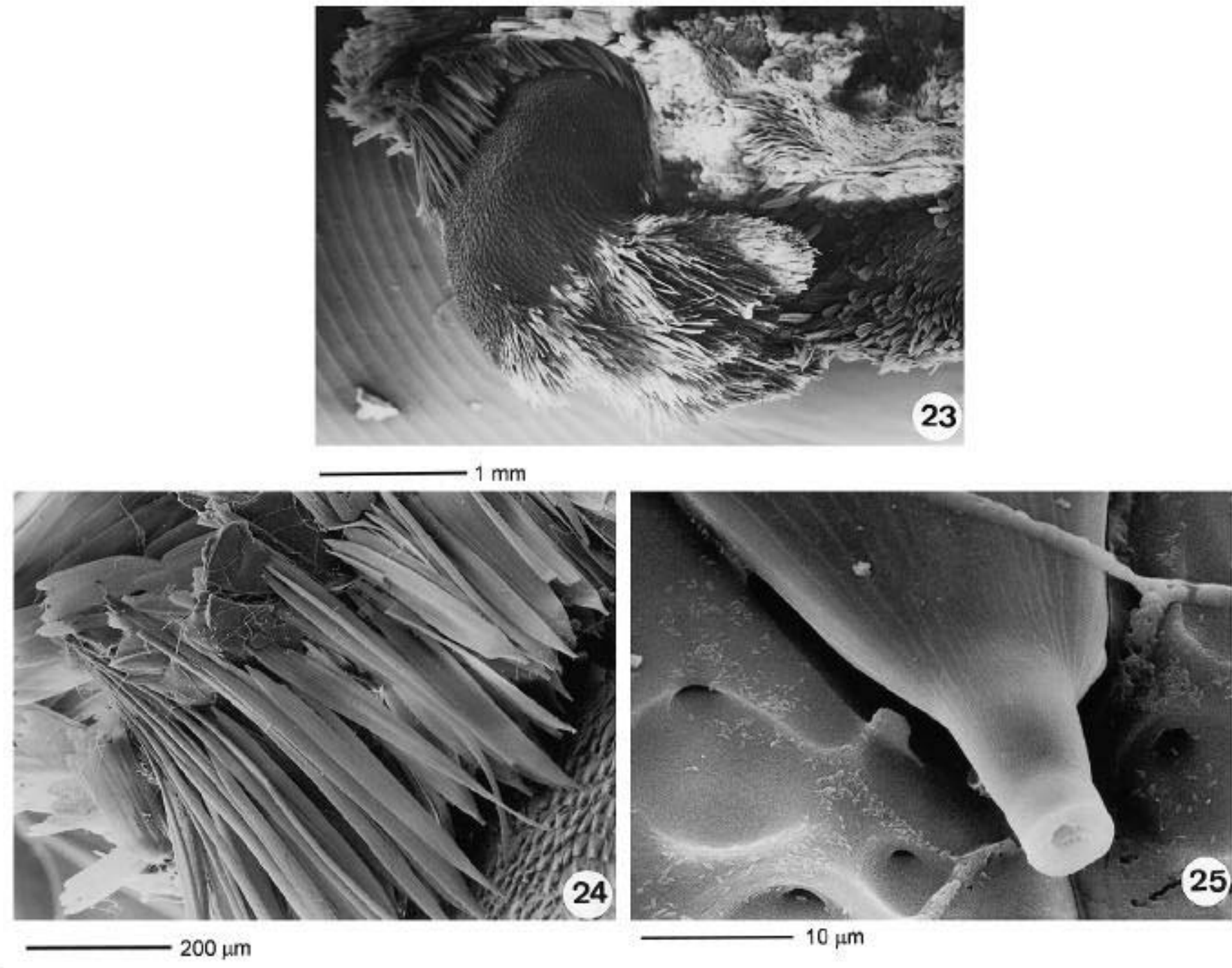

Figs. 23-25. Actinote catarina. 23, tampão genital; 24, detalhe do imbricamento das escamas; 25, detalhe da região basal da escama.

morfológico porém, o tampão apresenta o ápice sem contato com os esternos (Fig. 5) e A. genitrix, A. dalmeidaie A. catarina apresentam o ápice do tampão em contato parcial com o sétimo esterno com uma ligação abrupta em forma de degrau entre $\mathrm{o}$ VII esterno e a placa genital (Figs 17, 20 e 23).

Estas variações sugerem que o tampão genital e suas escamas possam ser usados como um caráter taxonômico auxiliar na identificação de algumas fêmeas de Actinote e como um caráter na filogenia dos Acraeinae Neotropicais que compreendem as espécies de Actinote, Altinote Potts, 1943 e Abananote Potts, 1943 para os quais ainda não há subsídios que indiquem sua monofilia ou não (LAMAs 1996). Estes dados podem somar àqueles já apresentados por PIERRE (1985), que refere-se aos mesmos como uma sinapomorfia para os grupos de espécies.

Agradecimentos. Ao Sr. Paulo Brixel, pela ajuda nas sessões de microscopia eletrônica de varredura, no Laboratório Central de Pesquisa e Desenvolvimento Convênio COPEL/UFPR; a Doutoranda Favízia Freitas de Oliveira pelas fotos coloridas, pós-graduação em Entomologia, UFPR; ao Dr. Jorge M. S. Bizarro pelo empréstimo dos exemplares de Acraea e ao Sr. Herbert Miers, Joinville, SC, pela doação dos exemplares de A. catarina.

\section{REFERÊNCIAS}

ANKen, R. H. 1996. On the taxonomic value of the morphology of wing scales in some Heliconiinae (Lepidoptera, Nymphalidae). Iheringia, Série Zoologia 81: 139-144.

Brown, K. S. \& R. B. Francini. 1990. Evolutionary strategies of chemical defense in aposematic butterflies: cyanogenesis in Asteraceae-feeding American Acraeinae. Chemoecology 1: 52-56.

Chapman, T. E. 1900. Note on the oviposition of Parnassius apollo. The Entomologist 33: 282.

D' Almeida, R. F. 1958. Ligeiras notas sôbre algumas Actinote do sudeste do Brasil (Lepidoptera-Rhopalocera). Boletim do Museu Nacional, n.s., Zoologia 178: 1-7. 
Eltringham, H. 1912. A monograph of the African species of the genus Acraea Fab. Transactions of the Entomological Society of London 1: 1-374.

Ehrlich, A. H. \& P. R. Ehrlich. 1978. Reproductive strategies in the butterflies: I. Mating frequency, plugging, and egg number. Journal of the Kansas Entomological Society 51(4): 666-697.

LAmAs, G. 1996. Lista comentada de los nombres propuestos para los Acraeini neotropicales, y su material-tipo (Lepidoptera: Nymphalidae, Heliconiinae). Revista Peruana de Entomologia 39: $29-48$

Marshall, A. K. 1901. On the female pouch in Acraea. The Entomologist 34: 73-75.

Mielke, C. G. C. 1994. Papilionoidea e Hesperioidea (Lepidoptera) de Curitiba e seus arredores, Paraná, Brasil, com notas taxonômicas sobre Hesperiidae. Revista Brasileira de Zoologia 11(4): 759 776.

Miller, J. S. 1987. Phylogenetic studies in the Papilioninae (Lepidoptera: Papilionidae). Bulletin of the American Museum of Natural History 186: $365-512$.

Pierre, J. 1985. Le sphragis chez les Acraeinae (Lepidoptera Nymphalidae). Annales de la Societé Entomologique de France 21 (4): 393 398.

Penz, C.m. \& R.B. Francini. 1996. New species of Actinote Hübner (Nymphalidae: Acraeinae) from southeastern Brazil. Journal of the Lepidopterists' Society 50 (4): 309-320.

Sourakov, A. \& T. C. Emmel. 1997. Mating habits in the genus Acraea, with a possible explanation for monosexual populations (Lepidoptera: Nymphalidae: Acraeinae). Tropical Lepidoptera 8 (suppl.3): 33 36. 